\title{
Environmental disasters as a factor of environmental pollution
}

\author{
Galina Semenova ${ }^{1,2, *}$ \\ ${ }^{1}$ Plekhanov Russian University of Economics, Stremyanny lane, 36, Moscow, Russia \\ ${ }^{2}$ Moscow Region State University, 24, Vera Voloshina Str., Mytishchi, Moscow Region, Russia
}

\begin{abstract}
An ecological catastrophe consists in a massive change in natural conditions that lead to a change in the environment and the death of living organisms. Disaster can be caused by both natural processes and human actions. Losses after such disasters are often irreparable. Economic reasons worse the ecological situation. Wastewater treatment plants are very expensive, so industrialists often prefer to save on and forget about the environment during the construction and operation of new production facilities. The pursuit of immediate profits without thinking about tomorrow, undoubtedly, deepens the crisis in the field of ecology, thereby resulting in environmental disasters. The subject of this study is global environmental disasters. The purpose of the study is to identify the influence of the negative impact of substances on the environment. Methodology. To study the topic, the world environmental disasters and the damage caused by their impact on the environment were systematized. Results - the damage (harm) from the negative impact on the environment was revealed, the calculation formulas were given.
\end{abstract}

\section{Introduction}

An environmental disaster is usually understood as an irreversible change in the natural complex, which can lead to the death of living beings. The definition indicates that these can be even the smallest species of organisms. An important type of this phenomenon is the water environmental disaster.

Sometimes an environmental crisis develops over a long period of time. Its ending is a global catastrophe. In Russia, scientists are actively discussing whether earthquakes, typhoons and other natural phenomena can be attributed to this type of similar problems. After all, the main features by which this "diagnosis" is made converge.

This phenomenon is usually determined by the following characteristics:

- gradual change in temperature and climate;

- animals migrate to other habitats;

- pollution of water, earth and air environments;

- destruction in certain places or over the entire surface of the biosphere screen;

- rupture of natural ties in nature associated with anthropogenic impact on water or other resources.

\footnotetext{
*Corresponding author: angela-1309.m@yandex.ru
} 
The main feature that allows separating environmental disasters from other problems is the impossibility of returning everything to its original state.

There are several ways to classify an environmental disaster. Methods are used that separate disasters by size and nature. Among them:

- global. Impact on the entire biosphere of the Earth;

- local. Impact on a specific ecosystem.

What can lead to an environmental disaster? The reasons that can lead to irreversible changes in nature do not always have an anthropological nature. But most of them are associated with human activities.

The reasons that can provoke a catastrophe are as follows:

- the phase of development of the biosphere, which implies the change of living organisms;

- natural phenomena;

- technical problems or accidents;

- harmful emissions from industrial enterprises;

- gradual accumulation of harmful elements due to human misbehavior and active elimination of natural conditions of the natural environment;

- oil spill;

- use of biological, atomic weapons.

Some researchers believe that the creation of psychotropic weapons should also be attributed to the factors that lead to disasters in the field of ecology. According to them, a person becomes uncontrollable, destroys his own kind, or is able to carry out actions that lead to great destruction. These actions will later become the cause of an environmental crisis or disaster. In Russia, this opinion is shared by the minimum number of specialists.

What consequences can come? The spectrum of adverse effects is so wide that researchers urge people to think about the possible disappearance of people and many countries. Also, after various disasters, the following is possible: the emergence of the "greenhouse effect"; the fallout of acid rain; the disappearance of fertile soils due to waterlogging, their transformation into a desert; decrease in the volume of food due to the disappearance of any plants or animals; the disappearance of fresh water available to people due to salinization of soils and water resources; the disappearance of any species of plants, animals, microorganisms and all life on planet Earth [3].

How to prevent an environmental disaster? For example, Russian legislation describes a large number of measures that should prevent environmental problems. These include: setting emission standards for industrial enterprises; recommendations for production technologies; organization of protective and sanitary zones; wastewater treatment obligations; reforestation obligations; prohibition and restrictions on conducting activities in sea waters, issuing quotas for fishing; a ban on hunting; supporting the Red Book; climatic studies, which make it possible to adjust the zones where the creation of industrial production is permissible, etc.

It must be remembered that any person can involuntarily become the cause of the death of any territory. Even if a small area on the planet can no longer recover, then this is a reason to do everything to prevent such a situation [2].

\section{Materials and Methods}

From an environmental disaster, environmental damage occurs. Environmental damage is formed under the influence of three groups of factors:

-impact (characterizes the degree of pollution of a particular element of the environment); 
-perception (objects that are negatively affected by pollution);

-state (reflects the level of normative economic indicators converting natural indicators into value ones).

There are various methods for determining harm based on the compensation principle of assessment and further compensation for the amount of harm in terms of the amount of costs necessary to determine the fact of harm, as well as to further eliminate its consequences and causes. This includes various costs required for the development of design and estimate documentation and those costs that need to be allocated to eliminate the committed violation and further restore the state of a certain object to the indicators observed until the violation was identified [1].

Let's consider the sources of environmental damage.

Harm due to the discharge of harmful substances. In this case, the calculation is carried out in accordance with the following characteristics: the mass of pollutants emitted from the enterprise; the intensity of the impact of these substances on a specific object; hazard class of pollutants in the event that their concentration is more than 10 times higher than in the background. After that, the calculation of environmental damage from environmental pollution is carried out on the basis of the state of the object, what type it belongs to and how valuable it is, as well as in accordance with some additional parameters, such as seasonality, etc. In this case, the value of a particular object is determined by the presence of any rare plants, natural medicinal resources in it, or belonging to objects subject to special protection.

Harm due to accidents. Quite often, there are situations when, due to some accidents at enterprises, the environment is sufficiently polluted by various inorganic and organic substances, including oil products, pesticides and many others, as a result of which they can even get into waste or drainage waters. In this case, the methods for calculating environmental damage provide for its determination in accordance with the mass of the substance emitted as a result of the accident, as well as the time during which no measures were taken to eliminate the resulting pollution. Again, the methodology provides for an additional calculation in accordance with the condition of the object to which the damage was caused, its type and value, as well as a number of additional factors.

Harm due to the discharge of domestic waste water from various ships. The method for calculating the prevented environmental damage or damage already inflicted provides for the determination of damage in accordance with the volume of the storage tank required for collecting domestic water or by the category of the ship, the number of people staying on it during this incident, as well as the time of continuous stay of the ship outside moorage.

Harm due to pollution by consumer and industrial waste in the form of garbage. The area of the object that has been contaminated with garbage is determined. If this object is some kind of reservoir, then in this case the area of the water area, as well as the bottom and coastal strips of the object polluted with this waste, is determined. The rest of the parameters are the same: the state of the object after causing damage to it, the seasonality, the type and value of the given object, but the degree of contamination of the given object with garbage or any other waste is added to them.

Harm due to dumping or disposal of consumption and production waste. Calculation of environmental damage is carried out in accordance with the mass of thrown bulky waste of consumption and production. In addition, the damage is calculated in accordance with the state of the object due to damage caused to it, as well as its value and type [3].

Let's consider how the calculation of damage (harm) by various negative influences is made.

Calculation of environmental damage from oil pollution of water bodies:

$$
\mathrm{Dw}=5 \times \mathrm{Ci} \times \mathrm{Cew} \times \mathrm{Nbw} \times \mathrm{Mw},
$$


Where Dw is the amount of payment for oil pollution of water bodies;

$\mathrm{Ci}$ - indexation coefficient;

Cew - the coefficient of the ecological situation and the ecological significance of the state of the water body;

$\mathrm{Nbw}$ - basic standard of payment for the discharge of one ton of oil into a water body within the established limit, rubles/t;

$\mathrm{Mw}$ - the mass of oil that got into the water body.

Calculation of environmental and economic damage from environmental pollution during fires and accidents:

$$
\text { De-e }=\text { De-e- a }+ \text { De-e w }+ \text { De-e s }
$$

Where De-e - environmental and economic damage from environmental pollution during fires and accidents;

De-e a - economic damage from air pollution, rubles;

De-e w- economic damage from pollution of water bodies, rubles;

De-e s - economic damage from land (soil) pollution, rubles.

Calculation of the amount of damage caused by negative impacts of substances (pollutants) to water bodies:

$$
\mathrm{D}=\mathrm{Cs} \times \mathrm{Cw} \times \mathrm{Cin} \times \mathrm{Cd} \times \sum \mathrm{Ni}
$$

Where $\mathrm{D}$ is the amount of damage, rubles;

Cs - coefficient taking into account natural and climatic conditions depending on the season;

$\mathrm{Cw}$ - coefficient taking into account environmental factors (condition of water bodies);

Cin - indexation coefficient;

$\mathrm{Cd}$ - coefficient that takes into account the duration of the negative impact of substances (pollutants) on a water body;

$\sum \mathrm{Ni}$ - rate for calculating the amount of damage in case of pollution of water bodies with the i-th (polluting) substance as a result of accidents.

All modern methods have different areas of use and are intended to calculate the harm to various components of the environment.

Situations often occur when different factors act negatively at the same time. For example, as a result of an earthquake, accidents occur at industrial facilities, which provokes the release of harmful substances. This indicates that it is necessary to provide for ways of protecting hazardous objects in different areas [4-9].

\section{Results}

Environmental disasters happen after the negligence of people who work in industrial plants. One mistake can cost thousands of lives. Unfortunately, environmental disasters happen quite often: gas leaks, oil spills, forest fires. Over the past century, a number of technogenic accidents have occurred on Earth, which have had a significant impact on the climate and the environment. In some cases, a person provokes natural sources of disasters.

One of the most striking examples when both types of exposure led to a common disaster is the accident at a nuclear power plant in Japan in 2011. The tsunami caused by tremors hit the country. This led to the destruction of a nuclear power plant, which was not designed for such a strike, despite its location in a seismically active zone. Radiation standards in the vicinity were exceeded thousands of times in the early days, hundreds now. The total death toll is more than 15 thousand people.

Leakage of petroleum products at CHPP-3 NTEC in Norilsk. At CHPP-3 NTEC, there was a depressurization of the fuel tank, followed by the ignition of oil products. More than 
21 thousand tons of fuel poured into the stream flowing into the Ambarnaya River. The damage to the environment caused by the accident is calculated. Ecosystem restoration at the site of a fuel spill can take 5-10 years. Federal Service for Supervision of Natural Resource Usage has calculated the damage and sent claims for voluntary compensation for damage to the Norilsk-Taimyr Energy Company, which is part of the Norilsk Nickel Group. The damage caused to water bodies due to pollution is equal to 147 billion 46 million rubles, to soils - 738 million rubles. The amount of damage to Arctic water resources is unprecedented.

Leakage of oil products from the Prestige tanker. In November 2002, the Prestige tanker sailing under the Bahamian flag was caught in a severe storm. It was located not far from the coast of Galicia, as a result of which a crack was formed on the ship, the length of which was $35 \mathrm{~m}$. More than 1000 tons of fuel oil were poured into the sea per day. The coastal authorities of Portugal and Spain did not allow the tanker to enter their ports, so the ship was forced to leave far from the coast. The Prestige sank 7 days after receiving the hole. It sank to a depth of over $3500 \mathrm{~m}$. 70 million liters of oil ended up in the sea, which led to the formation of a large slick. The death of all representatives of the marine flora and fauna was observed in this part. The damage amounted to 4 billion euros, the consequences were eliminated by more than 300 thousand volunteers [4].

Usinsk disaster. The largest oil spill happened in 1994. It is known as the Usinsk disaster. Several breaches were formed in the oil pipeline, as a result of which over 100,000 tons of oil products were spilled. In the places where the spill happened, flora and fauna were almost destroyed. The area received the status of an environmental disaster zone.

Khanty-Mansiysk and Bryansk disasters. An oil pipeline burst near Khanty-Mansiysk in 2003. More than 100,000 tons of oil flowed into the Mulymya River. Animals and plants died out both in the river and on the ground in this area. Another disaster happened near Bryansk in 2006, when 5 tons of oil spilled on the ground over 10 sq. km. Water resources in this radius have been polluted. An environmental disaster occurred due to a leak in the Druzhba oil pipeline.

In 2016, two environmental disasters have already happened. Near Anapa, in the village of Utash, oil leaked from old wells that are no longer in use. The size of soil and water pollution is about a thousand square meters, hundreds of waterfowl have died. On Sakhalin, more than 300 tons of oil spilled into the Urkt Bay and the Gilyako-Abunan River from a non-working oil pipeline.

Wreck of the Exxon Valdez tanker. The Exxon Valdez tanker transported oil in 1989. The ship was sailing from the coast of Alaska and heading to California (Long Beach) through Prince William Sound. As a result of criminal negligence on the part of the ship's management, more than 40 million liters of oil leaked into the sea. A number of experts believe that the figure was underestimated. As a result of the disaster, more than $2,400 \mathrm{~km}$ of the coast were damaged, causing irreparable damage to flora and fauna.

Bhopal disaster. As a result of the environmental disaster in Bhopal, more than 18 thousand people died and the environment was severely damaged. An enterprise located in India produced pesticides needed in agriculture. To reduce the cost of work, the management decided to abandon imported raw materials, using a more complex production process that poses a danger to both people and the environment. In July 1984, work was carried out on equipment that did not meet safety requirements. As a result of the influence of several factors, vapors of one of the harmful substances were released, which caused the rupture of the emergency valve. The consequence of this was the release of poisonous vapors into the atmosphere, which, having turned into a cloud, covered the city within a radius of $2 \mathrm{~km}$ from the enterprise, where the residential areas and the train station were located. 
Disappearance of the Aral Sea. The Aral Sea ranked 4th in the ranking of the largest lakes. Its waters were used to replenish the Amu Darya and Syr Darya, the water resources of which were used to irrigate fields. Mistakes in the construction of agricultural canals led to the fact that the lake began to shallow. Specialists found chemicals and salt in the exposed areas. The water began to evaporate quickly. Now the size of the lake is $10 \%$ of what it was originally. More than 140 species of vertebrates living in the Aral Sea died. Only 38 left.

Fire at the Piper Alpha oil platform. An environmental disaster happened in July 1988. The platform was engaged in the extraction of such minerals as oil and gas. On 6 July, a fire broke out at Piper Alpha, killing 167 workers. The unwillingness of people, their uncoordinated and ill-considered actions led to the fact that the fire lasted for a long time. As a result, monetary losses amounted to more than $\$ 3$ billion, but the damage to the natural environment has not been calculated.

Explosion of an oil platform in the Gulf of Mexico. The explosion of the Deepwater Horizon oil platform on April 20, 2010 led to the fact that a huge volume of oil products was thrown into the world ocean. Due to a technical malfunction, an accident occurred on the platform, and Deepwater Horizon itself went under water. The entire colossal nature of the damage cannot be accurately determined even by specialists, and this man-made disaster was one of the most destructive for the biosphere during the entire existence of mankind. As a result of the oil spill, which lasted for 152 days, 75 thousand square kilometers of the area of the Gulf of Mexico was covered with an oil slick. All states with access to the Gulf of Mexico suffered, Alabama was the hardest hit, and Mississippi, Florida and Louisiana were also severely damaged. The oil spill threatened the lives of approximately 400 species of rare animals. On the coast, dozens of birds and amphibians died. According to the Department of Specially Protected Resources, at the time of the oil spill, an outbreak of cetacean mortality was recorded within the boundaries of the Gulf of Mexico. The main economic damage was suffered by the tourist, fishing and oil industries in the United States. [4,5]

Chernobyl disaster. In April 1986, an explosion occurred at the Chernobyl nuclear power plant. It led to the destruction of one of the nuclear reactors, as a result of which a large amount of radioactive elements were released into the atmosphere. People who were within a $30 \mathrm{~km}$ radius of the disaster area were evacuated. Their number has reached 115 thousand people. To eliminate the consequences of the environmental disaster, more than 600 people were involved, most of whom subsequently died from radiation contamination.

We have already witnessed many environmental disasters on the planet. Passive observation is not enough. To follow the correct path to solving environmental problems, it is necessary to understand the essence of natural crises in general and its individual manifestations, to draw conclusions from the mistakes made. Otherwise, the crisis will develop into an irreversible ecological catastrophe with the complete destruction of the biosphere. Environmental issues should now come first on the list of urgent issues.

\section{Discussion}

The problems of environmental disasters are discussed at various conferences and symposia. For example, at a conference in Geneva, a report on the world's forest resources was presented, according to which, the world's forest area decreased by 178 million hectares from 1990 to 2020, which is roughly the size of Libya. According to TASS, the report was prepared by forestry specialists of the UN Food and Agriculture Organization. At the same time, the report notes that in recent years, the rate of forest loss in the world has slowed down. So, over the past five years, 10 million hectares of forests disappeared annually, and in the previous five-year period, 12 million. Currently, the global forest area 
is 4.06 billion hectares (about $31 \%$ of the earth's land area). The reduction of this area over the past 30 years is especially felt in Africa and South America. The list of countries where forests have decreased over the past 10 years include Brazil, the Democratic Republic of Congo and Indonesia.

Maria Fernanda Suarez, Colombian Minister of Mines and Energy, raised the main question - how to reduce harmful emissions? In her opinion, the industry will now have to solve more issues related to responsible business conduct, including in the field of ecology, than in the past, when thinking mainly about the cost of production.

The opinions of all ecologists come down to one thing "The planet's ecological cataclysms can be solved if each person remembers that he has an impact on nature every day. Humanity needs to conserve water and energy resources. Humanity is looking for an alternative fuel that will help keep our land clean".

\section{Conclusions}

The occurrence of natural disasters of an ecological nature leads to climate change throughout the planet:

- the greenhouse effect is increasing;

- the relief changes with the formation of territories unsuitable for the development of the biosphere;

- acid rain falls;

- biological organisms disappear.

To prevent environmental disasters, it is necessary to exclude the human impact that manifests itself in man-made accidents. For this, all possible natural factors that may affect the performance of infrastructure facilities must be taken into account. As part of maintaining the climate balance, work should be done to reduce resource extraction and restore the planet's ozone layer [2].

It is a fact that environmental disasters greatly change the world around us. As a result of them, water, soil and atmosphere are polluted, many representatives of the animal world die. Environmental disasters are often caused by humans.

\section{References}

1. G.I. Peshcherov, Collection of reports of the X International Forum "Ecology" (Moscow, 2019)

2. G. Semenova, E3S Web of Conferences 157, 02023 https://doi.org/10.1051/e3sconf/202015702023

3. Arefiev, N., Mikhalev, M., Zotov, D., Zotov, K., Vatin, N., Nikonova, O., Skvortsova, O., Pavlov, S., Chashina, T., Kuchurina, T., Petrochenko, M., Rechinsky, A. Physical modeling of suspended sediment deposition in marine intakes of nuclear power plants. Procedia Engineering. 2015. 117(1). Pp. 32-38. DOI:10.1016/j.proeng.2015.08.120.

4. G. Semenova, E3S Web of Conferences 138, 02012 (2019) https://doi.org/10.1051/e3sconf/201913802012

5. Recycling Basics (United States Environmental Protection Agency) https://www.epa.gov/recycle/recycling-basics 
6. N. Tulebayeva, D. Yergobek, G. Pestunova, A. Mottaeva, Z. Sapakova, E3S Web of Conferences 159, 01012 (2020) https://doi.org/10.1051/e3sconf/202015901012

7. Vatin, N.I., Chechevichkin, V.N., Chechevichkin, A.V., Shilova, Y.S. Possible applications of clinoptilolites for natural water purification. Magazine of Civil Engineering. 2013. 37(2). DOI:10.5862/MCE.37.12.

8. Vatin, N.I., Chechevichkin, V.N., Chechevichkin, A.V., Shilova, Y., Yakunin, L.A. Application of natural zeolites for aquatic and air medium purification. Applied Mechanics and Materials. 2014. 587-589. Pp. 565-572. DOI:10.4028/www.scientific.net/AMM.587-589.565.

9. Vatin, N.I., Chechevichkin, V.N., Chechevichkin, A.V., Shilova, Y.S. Possible applications of clinoptilolites for natural water purification. Magazine of Civil Engineering. 2013. 37(2). DOI:10.5862/MCE.37.12.

10. L. Pushkareva, M. Pushkarev E3S Web of Conferences 135, 04070 (2019) doi:10.1051/e3sconf/201913504070 